\title{
Long non-coding RNA LINC00460 serves as a potential biomarker and oncogene via regulation of the miR-320b/PBX3 axis in acute myeloid leukemia
}

\author{
QIANG ZHUANG $^{1 *}$, ZHENLIN JIN $^{1 *}$, XIANGKUO ZHENG $^{2}$, TING JIN $^{1}$ and LINA XIANG ${ }^{3}$ \\ ${ }^{1}$ Department of Hematology, The First Affiliated Hospital of Wenzhou Medical University; ${ }^{2}$ Department of \\ Experimental Center, School of Laboratory Medicine and Life Sciences, Wenzhou Medical University; ${ }^{3}$ Department of \\ Emergency, The First Affiliated Hospital of Wenzhou Medical University, Wenzhou, Zhejiang 325035, P.R. China
}

Received April 19, 2020; Accepted October 16, 2020

DOI: $10.3892 / \mathrm{mmr} .2021 .12074$

\begin{abstract}
Long non-coding RNA 00460 (LINC00460) has been reported to be involved in the tumorigenesis of various cancer types. However, the function of LINC00460 in acute myeloid leukemia (AML) remains elusive. Therefore, the present study aimed to investigate the role of LINC00460 in AML. The expression of LINC00460 in the serum of 80 diagnosed patients with AML and 67 healthy controls was measured via reverse transcription-quantitative polymerase chain reaction, and the results were compared with clinical features and patient outcomes. The expression of LINC00460 in 45 patients with cytogenetically normal-AML (CN-AML) was also assayed. Receiver operating characteristic (ROC) curves were generated to evaluate the sensitivity and specificity of serum LINC00460. In addition, the effects of LINC00460 on the viability, cell cycle distribution and apoptosis of AML cells were investigated. Bioinformatics tools were used to identify the possible mechanisms of how LINC00460 affects AML cells. It was found that the expression of LINC00460 was significantly upregulated in the serum of patients with AML and those with CN-AML. Higher expression of serum LINC00460 was positively associated with French-American-British classification and cytogenetics. Furthermore, ROC curve analyses demonstrated that serum LINC00460 could differentiate patients with AML from healthy individuals with an area under the curve of 0.8488 (95\% CI, 0.7697-0.9279). The serum LINC00460
\end{abstract}

Correspondence to: Dr Lina Xiang, Department of Emergency, The First Affiliated Hospital of Wenzhou Medical University, 1 Nanbaixiang Street, Ouhai, Wenzhou, Zhejiang 325035, P.R. China E-mail: linaxnb320@sohu.com

*Contributed equally

Key words: acute myeloid leukemia, long non-coding RNA 00460 , biomarker, prognosis, microRNA-320b, PBX homeobox 3 expression was also significantly decreased when the patients achieved complete remission. Kaplan-Meier analysis indicated that patients with high serum LINC00460 expression had a shorter overall survival time compared with the low serum LINC00460 expression group. Knockdown of LINC00460 inhibited viability, while inducing cell cycle arrest and apoptosis in AML cells. LINC00460 was also a decoy of microRNA (miR)-320b, which can further inhibit the expression of PBX homeobox 3 (PBX3). Collectively, the results suggested that LINC00460 may be applied as a potential diagnostic and prognostic biomarker for patients with AML. It was identified that LINC00460 may exert its effects, at least partly, via the miR-320b/PBX3 axis in AML.

\section{Introduction}

Acute myeloid leukemia (AML) is a heterogeneous malignant disorder characterized by uncontrolled proliferation of hematopoietic progenitor cells and differentiation arrest (1). AML is the most common form of acute leukemia and the second most common type of leukemia diagnosed worldwide (2). The incidence of AML is directly proportional to an increase in age (3). Previous studies have reported that AML results from mutations in different genes involved in the processes of cell proliferation, survival and apoptosis (4). For instance, mutations in RAS, tyrosine kinase signaling pathways $(C B L$, FLT3, JAK2, KIT, PTPN11), chromatin modifiers (ASXL1/2, $B C O R / L 1, T E T 2$ ) and an additional 50 genes have been found to be associated with occurrence of AML (5). According to cytogenetic information, patients with AML can be divided into three risk-based subgroups: Favorable, intermediate and poor (6). Although great progress has been made in chemotherapy-based regimens and hematopoietic stem cell transplantation, the prognosis of AML remains unsatisfactory, and the 5-year survival rate is $<30 \%$ (7). Early diagnosis of AML can increase the overall survival rate of patients with AML (3). Therefore, it is necessary to identify novel and sensitive biomarkers for the diagnosis and prognosis of patients with AML.

Long non-coding RNAs (IncRNAs) are a group of non-coding RNAs that are between $200 \mathrm{bp}$ and $100 \mathrm{~kb}$ in 
size (8). Due to the absence of open reading frames, lncRNAs lack the ability to encode proteins (9). Mounting evidence has suggested that lncRNAs serve essential roles in the regulation of various cellular biological processes, such as proliferation, differentiation, metabolism and programmed cell death (10). Aberrant expression of non-coding RNAs has been observed in multiple diseases, including cancer (11). To date, numerous IncRNAs, such as nuclear paraspeckle assembly transcript 1 (NEAT1), HOX transcript antisense RNA (HOTAIR) and metastasis-associated lung adenocarcinoma transcript 1 (MALAT1), have been identified as important factors in the regulation of AML (12). IncRNA 00460 (LINC00460) is a newly discovered lncRNA located on human chromosome $13 \mathrm{q} 33.2$ with a transcript size of $935 \mathrm{bp}$ (13). Previous studies have revealed that LINC00460 functions as an oncogene in various malignancies, such as lung cancer, colorectal cancer, gastric cancer, ovarian cancer and osteosarcoma (14-18). However, the status of LINC00460 expression and its prognostic significance in AML remain elusive. To address this question, the present study aimed to investigate the diagnostic and prognostic value of serum LINC00460 in patients with AML.

MicroRNAs (miRNAs/miRs) are another type of non-coding RNA, with a size of $\sim 20$ nucleotides, that can inhibit target mRNAs at the post-transcriptional level (19). Previous studies have reported that miRNAs serve essential roles in the initiation and progression of various cancer types, including AML (20). Among the various miRNAs, miR-320b has been implicated in the tumorigenesis of different cancer types, such as glioma, colorectal cancer, lung cancer and prostate cancer (21-24). However, knowledge regarding the role of miR-320b in AML is currently lacking.

PBX homeobox 3 (PBX3) is a homeodomain-containing transcription factor that belongs to the pre-B cell leukemia family (25). The role of PBX3 has been extensively studied in AML. For instance, enhanced expression of PBX3 with its cofactor Meis homeobox 1 (MEIS1) can transform normal hematopoietic stem cells into AML in mice (26). Furthermore, silencing PBX3 can increase the sensitivity of AML cells to chemotherapy agents (27). However, to the best of the authors' knowledge, there are no reports investigating the association between LINC00460, miR-320b and PBX3.

The present study examined the prognostic and biological roles of LINC00460 in AML. The in vivo expression of LINC00460 was measured by reverse transcription-quantitative polymerase chain reaction (RT-qPCR). The effects of LINCO00460 on the viability, cell cycle distribution and apoptosis were assayed in vitro. Furthermore, the mechanisms underlying the functions of LINCO00460 were also investigated. The findings suggested that LINC00460 might be a prognostic biomarker and therapeutic target for AML.

\section{Materials and methods}

Patient samples. A total of 80 diagnosed AML cases were recruited between December 2018 and January 2010 at the First Affiliated Hospital of Wenzhou Medical University, which were classified as favorable-risk cytogenetic (20 subjects), intermediate-risk cytogenetic (42 subjects) and poor-risk cytogenetic (18 subjects). The patients consisted of 38 females and 42 males, aged 37-87 years. The median value of expression of LINC00460 was 2.36 and was used as a cutoff value. All patients were divided into two groups: High LINC00460 expression group $(>2.36 ; n=36)$ and low LINC00460 expression group $(\leq 2.36 ; n=44)$. Of the 80 patients with AML, 45 cases were classified as cytogenetically normal-AML (CN-AML). The diagnosis of patients with AML was made according to the French-American-British (FAB) and World Health Organization criteria combined with immunophenotyping and cytogenetic analysis (28). Additionally, 67 healthy volunteers without any type of malignancy or other benign disease were enrolled as controls.

Firstly, the serum $(0.5 \mathrm{ml})$ was collected from all patients before any treatment. After receiving different treatments [chemotherapy and $(n=41) /$ or targeted therapy $(n=1)], 42$ patients achieved complete remission (CR), the serum $(0.5 \mathrm{ml})$ of these patients was collected again.

This research was approved by the Ethics Committee of Wenzhou Medical University. Written informed consent was obtained from all patients prior to participation in the study.

Cell culture and transfection. Human bone marrow stromal cells (HS-5) and human AML cells (THP-1, KG-1, K562 and HL-60) were purchased from the Cell Bank of Shanghai Institute of Biological Sciences, Chinese Academy of Sciences. All cells were cultured in RPMI-1640 medium (HyClone; Cytiva) supplemented with 10\% FBS (Gibco; Thermo Fisher Scientific, Inc.), $100 \mathrm{U} / \mathrm{ml}$ penicillin and $100 \mu \mathrm{g} / \mathrm{ml}$ streptomycin (Thermo Fisher Scientific, Inc.) at $37^{\circ} \mathrm{C}$ with $5 \% \mathrm{CO}_{2}$.

For transfection, small interfering RNA (siRNA) against LINC00460 (si-LINC00460), negative control siRNA (si-NC), pcDNA3.1 vector, LINC00460 overexpression vector (pcDNA-LINC00460), miR-320b mimic, miR-NC, miR-320b inhibitor, miR-NC inhibitor and PBX3 overexpression vector (pcDNA-PBX3) were synthesized by Suzhou GenePharma Co., Ltd. The target sequences were as follows: si-LINC00460, 5'-CACACUUCTCGGCUAAG-3'; si-NC, 5'-AACAGGCAU CCUACGACGCCA-3'; miR-320b mimics, 5'-AAAGCUGGG UUGAGAGGGCAA-3'; miR-NC, 5'-AAUUCUCCGAAC GUGUCACTT-3'; miR-320b inhibitor, 5'-UUGCCCUCU CAACCCAGCUUU-3'; and miR-NC inhibitor, 5'-AAACAC GGUUAUAUCACCAUCGCAUUA-3'. All transfections were conducted using Lipofectamine ${ }^{\circledR} 2000$ (Thermo Fisher Scientific, Inc.) according to the manufacturer's instructions. Cells were seeded into 6 -well plate at the density of $3 \times 10^{5}$ cells/well in $2 \mathrm{ml}$ complete medium. After $24 \mathrm{~h}$ of incubation at $37^{\circ} \mathrm{C}$, the medium was changed to $300 \mu \mathrm{l}$ Opti-MEM (Gibco; Thermo Fisher Scientific, Inc.) containing $2 \mu \mathrm{g}$ pcDNA-PBX3 or $2 \mu \mathrm{g}$ pcDNA-LINC00460 with $50 \mathrm{mM}$ siRNA. To modulate the expression of miR-320b, $20 \mathrm{mM}$ miRNA mimics or $20 \mathrm{mM}$ miRNA inhibitor in $200 \mu \mathrm{l}$ Opti-MEM containing $5 \mu 1$ Lipofectamine ${ }^{\circledR} 2000$ was added into each well. A total of $4 \mathrm{~h}$ after incubation, $1.5 \mathrm{ml}$ complete medium was added into each well and the cells were continually incubated at $37^{\circ} \mathrm{C}$ for $48 \mathrm{~h}$ for following experiments. Experiments were repeated $\geq 3$ times.

Cell viability assay. Cell viability was measured using the MTT assay as described previously (29). Cells were seeded in 6 -well plates at a density of $1 \times 10^{5}$ cells/well. 
After transfection for the indicated time, $20 \mu 10.5 \mathrm{mg} / \mathrm{ml}$ MTT (Beyotime Institute of Biotechnology) was added to the medium and incubated for another $4 \mathrm{~h}$ at $37^{\circ} \mathrm{C}$. Before measurement, $150 \mu \mathrm{l}$ DMSO was added, and a microplate reader (SpectraMax 190; Molecular Devices, LLC) was used to measure the optical density at $450 \mathrm{~nm}$. Experiments were repeated $\geq 3$ times.

Cell cycle measurement. Cell cycle status was detected via flow cytometry (FACScan; Becton, Dickinson and Company) and analyzed with FlowJo v10.4 software (FlowJo LLC). Following the different transfections as described above, the cells were harvested and cell pellets were fixed in cold ethanol (75\%) overnight at $-20^{\circ} \mathrm{C}$. The fixed cells were then resuspended in $1 \mathrm{mg} / \mathrm{ml}$ RNase A (Sigma-Aldrich; Merck KGaA) in PBS and incubated for $1 \mathrm{~h}$ at $37^{\circ} \mathrm{C}$. The cells were stained with $50 \mu \mathrm{g} / \mathrm{ml}$ PI (Sigma-Aldrich; Merck KGaA) for $0.5 \mathrm{~h}$ at room temperature in the dark. The cells were then analyzed, and the results are presented as the mean values from three independent measurements. Experiments were repeated $\geq 3$ times.

Cellular apoptosis measurement. The apoptosis of cells was measured using the Cell Death Detection ELISA ${ }^{\text {plus }}$ kit (Roche Diagnostics $\mathrm{GmbH}$ ) according to the manufacturer's instructions. The amount of histone-coupled DNA was quantified by measuring the absorbance at $405 \mathrm{~nm}$ by the BioTek synergy multimode microplate reader (BioTek Instruments, Inc.). The results were analyzed by the Gen5 v1.0 (BioTek Instruments, Inc.). Experiments were repeated $\geq 3$ times.

Caspase-3 activity assay. The activity of caspase-3 was measured using the caspase-3 Activity Assay kit (Fluorometric; Abcam) according to the manufacturer's instructions. Experiments were repeated $\geq 3$ times.

$R N A$ purification and RT-qPCR. Whole blood samples (5 ml) were obtained from the healthy controls and patients with AML before receiving any therapy. All serum specimens were centrifuged at $500 \mathrm{xg}$ for $5 \mathrm{~min}$ and then centrifuged at $3,000 \times \mathrm{g}$ for $5 \mathrm{~min}$, both at $4^{\circ} \mathrm{C}$. Serum samples were then stored at $-80^{\circ} \mathrm{C}$ until further analysis.

Total RNA was isolated using TRIzol ${ }^{\circledR}$ reagent (Thermo Fisher Scientific, Inc.) according to the manufacturer's instructions. The quality and concentration of RNA were measured using a NanoDrop ND-1000 (Thermo Fisher Scientific, Inc.). Total RNA was reverse transcribed into cDNA using the PrimerScript ${ }^{\mathrm{TM}}$ RT reagent kit (Takara Biotechnology Co., Ltd.). The reverse transcription was conducted at $65^{\circ} \mathrm{C}$ for $10 \mathrm{~min}$. qPCR was performed on an Applied Biosystems 7500 Detection System (Applied Biosystems; Thermo Fisher Scientific, Inc.) using SYBR Premix ExTaq (Takara Biotechnology Co., Ltd.) according to the manufacturer's instructions. The thermocycling conditions were: $95^{\circ} \mathrm{C}$ for $10 \mathrm{~min}$, followed by 40 cycles of $95^{\circ} \mathrm{C}$ for $5 \mathrm{sec}$ and $55^{\circ} \mathrm{C}$ for $5 \mathrm{sec}$ and $72^{\circ} \mathrm{C}$ for $5 \mathrm{sec}$, followed by $73^{\circ} \mathrm{C}$ for $30 \mathrm{sec}$ as a final extension. The relative expression of LINC00460 was assessed using the comparative $2^{-\Delta \Delta C q}$ method (30). The expression levels of LINC00460 and miR-320b were normalized to the expression levels of
GAPDH and U6, respectively. The following primers were used:LINC00460forward,5'-GGATGAACCACCATTGCC-3' and reverse, 5'-CCCACGCTCAGTCTTTCT-3'; miR-320b forward, 5'-TCCGAAACGGGAGAGTTGG-3' and reverse, 5'-GTGCAGGGTCCGAGGT-3', GAPDH forward, 5'-AGA AGGCTGGGGCTCATTTG-3' and reverse, 5'-AGGGGC CATCCACAGTCTTC-3'; and U6 forward, 5'-GCTTCGGCA GCACATATACTAAAAT-3' and reverse, 5'-CGCTTCACG AATTTGCGTGTCAT-3'. Experiments were repeated $\geq 3$ times.

Western blot analysis. Total cell lysates were collected using RIPA buffer (Beyotime Institute of Biotechnology). The concentration of proteins was measured using a BCA kit (Beyotime Institute of Biotechnology). Equal amounts of protein $(20 \mu \mathrm{g})$ were subjected to $12 \%$ SDS-PAGE and then transferred to PVDF membranes (Beyotime Institute of Biotechnology). The membranes were blocked with $10 \%$ skimmed milk for $1 \mathrm{~h}$ at room temperature and then incubated with the primary antibodies at $4^{\circ} \mathrm{C}$ overnight. The following primary antibodies were used: Bcl-2 (cat. no. 1507; 1:1,000), Bcl-xl (cat. no. 2762; 1:1,000), caspase-3 (cat. no. 14220; 1:1,000), PBX3 (cat. no. ab183849; 1:1,000; Abcam, USA), GAPDH (cat. no. 5174; 1:5,000). The membranes were washed with PBS and then incubated with secondary antibody at room temperature for $1 \mathrm{~h}$. The following secondary antibodies were used: HRP linked anti-mouse antibody (cat. no. 7076; 1:5,000), HRP linked anti-rabbit antibody (cat. no. 7074; 1:5,000). All antibodies were purchased from Cell Signaling Technology, Inc., and diluted at the ratio recommended by the manufacturer. Finally, the protein bands were visualized using the ECL reagent (Beyotime Institute of Biotechnology). Images were analyzed using Chemidoc Touch Imaging System v1.2 (Bio-Rad Laboratories, Inc.). The experiments were repeated $\geq 3$ times.

Dual-luciferase assays. The wild-type (WT) and mutant (MUT) fragments of LINC00460 and the 3'-untranslated region (UTR) of PBX3 containing the miR-320b targeting sequences were synthesized and inserted into the pGL3 promoter vector (Promega Corporation). Cells were seeded into 6-well plate at the density of $3 \times 10^{5}$ cells/well in $2 \mathrm{ml}$ complete medium. After $24 \mathrm{~h}$ of incubation at $37^{\circ} \mathrm{C}$, the medium was changed to $500 \mu \mathrm{l}$ Opti-MEM (Gibco; Thermo Fisher Scientific, Inc.) containing $1 \mu \mathrm{g}$ plasmid, $20 \mathrm{mM}$ miRNA mimics and $5 \mu \mathrm{l}$ Lipofectamine ${ }^{\circledR} 2000$ (Invitrogen; Thermo Fisher Scientific, Inc.). Cells were then cultured at $37^{\circ} \mathrm{C}$. Finally, $48 \mathrm{~h}$ after transfection, cells were collected and the Dual-Luciferase Reporter Assay system (Promega Corporation) was used to measure luminescence. Renilla luciferase activity was used to normalize the firefly luciferase activity. Experiments were repeated $\geq 3$ times.

Bioinformatic analysis. StarBase Ver 3.0 (http://starbase. sysu.edu.cn) and TargetScan Ver 3.1 (http://www.targetscan. org/mamm_31/) were used to predict the potential binding miRNAs of LINC00460 and targets of miR-320b.

Statistical analysis. Statistical analyses were performed using SPSS 18.0 (SPSS, Inc.) or GraphPad 8.0 (GraphPad Software, 
A

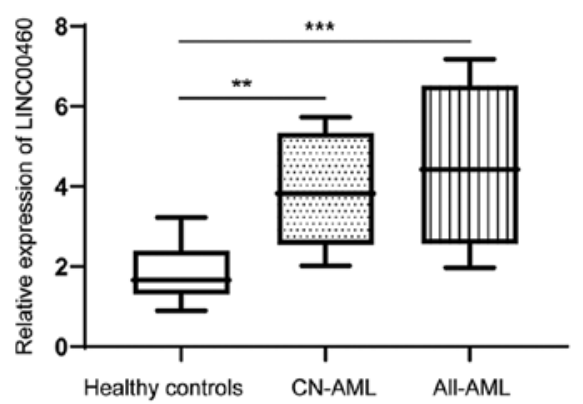

B

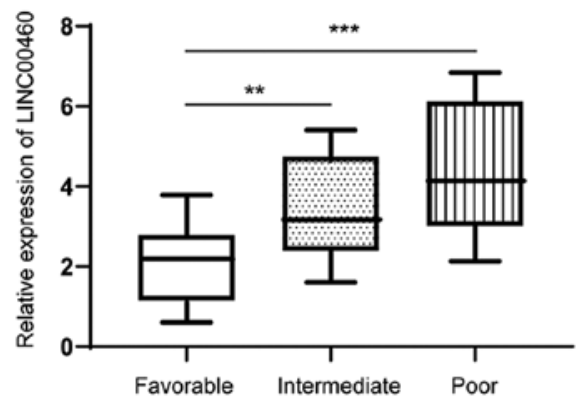

C

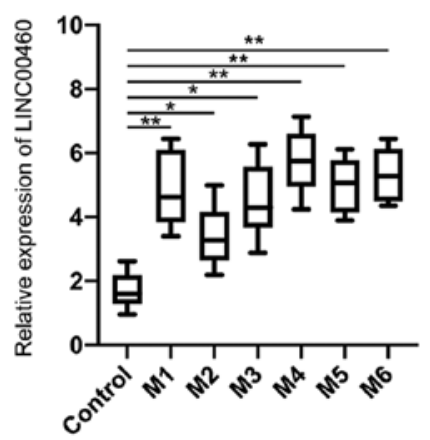

D

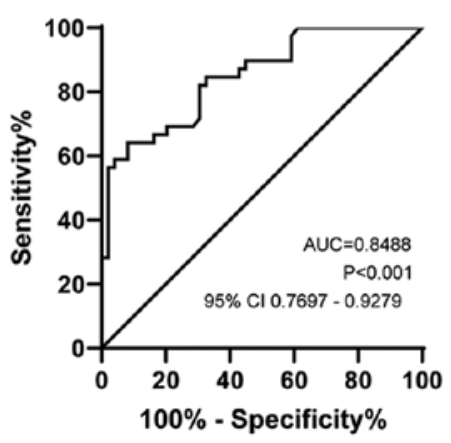

E

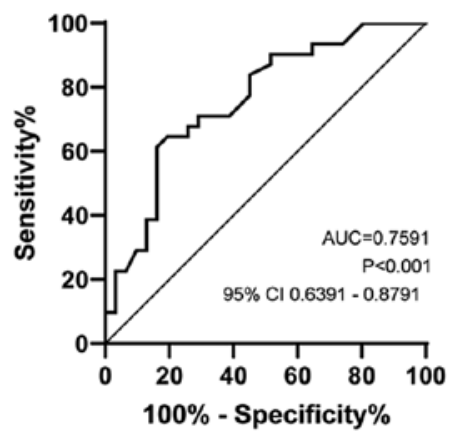

Figure 1. Expression of LINC00460 is significantly upregulated in patients with AML. (A) Expression of LINC00460 was compared between healthy controls, patients with CN-AML and patients with total AML. (B) Expression of LINC00460 was compared between different cytogenetic groups. (C) Expression of LINC00460 was compared between different French-American-British subtype groups (M1: Acute myeloblastic leukemia with minimal maturation; M2: Acute myeloblastic leukemia with maturation; M3: Acute promyelocytic leukemia; M4: Acute myelomonocytic leukemia; M5: Acute monocytic leukemia; M6: Acute erythroid leukemia; M7: Acute megakaryoblastic leukemia). (D) ROC analysis for the diagnosis of patients with AML using serum LINC00460 in patients with AML and healthy controls. (E) ROC analysis for the diagnosis of patients with CN-AML using serum LINC00460 in patients with AML and healthy controls. ${ }^{*} \mathrm{P}<0.05 ;{ }^{* *} \mathrm{P}<0.01 ;{ }^{* * *} \mathrm{P}<0.001$. AML, acute myeloid leukemia; LINC00460, long non-coding RNA 00460; AUC, area under the curve; CN-AML, cytogenetically normal-AML; ROC, Receiver operating characteristic.

Inc.) software. Data were presented as mean \pm standard deviation. The difference in the relative serum LINC00460 expression between groups was determined using the Mann-Whitney U test or Kruskal-Wallis test followed by Dunn's post hoc test. The median value of LINC00460 expression was used as the cut-off value to designate the patients with AML into a high LINC00460 group and a low LINC00460 group. A receiver operating characteristic (ROC) curve and the area under the curve (AUC) were used to assess the diagnostic value of serum LINC00460 expression in patients with AML and healthy controls. The Pearson $\chi^{2}$ test was used to assay intergroup differences. The Cox proportional hazards regression model was applied for univariate and multivariate analyses to estimate the prognostic factors for survival prediction. Survival curves were constructed via Kaplan-Meier survival analysis with the log-rank test. Paired Student's t-test and One-way ANOVA followed by the post hoc Tukey test were applied for comparing the difference between two groups or multiple groups, respectively. $\mathrm{P}<0.05$ was considered to indicate a statistically significant difference.

\section{Results}

Expression of LINCO0460 is upregulated in patients with $A M L$. First, the expression of LINC00460 in serum from 80 patients with AML and 67 healthy controls was measured via RT-qPCR. LINC00460 expression was significantly upregulated in patients with AML or CN-AML compared with those in healthy controls (Fig. 1A). Next, the patients with AML were divided into favorable, intermediate and poor groups according to their cytogenetic features (31). It was identified that LINC00460 expression in patients with AML with intermediate or poor cytogenetic risk subtypes was greatly increased compared with that in patients with favorable cytogenetic risk subtypes (Fig. 1B). Moreover, the expression of LINC00460 was compared among different FAB subtypes, but there was no significant difference among the various subtypes (Fig. 1C). ROC curve analysis demonstrated that serum LINC00460 could differentiate patients with AML from healthy controls with an AUC value of 0.8488 (Fig. 1D). In addition, serum LINC00460 could serve as a reliable biomarker for differentiating patients with $\mathrm{CN}-\mathrm{AML}$ from healthy controls with an AUC value of 0.7591 (Fig. 1E).

Association between the expression of LINC00460 and clinicopathologic features of $A M L$. The correlation between the expression of serum LINC00460 and the clinicopathological characteristics of AML was analyzed. The 80 patients with AML were grouped into a high serum LINC00460 group $(n=36)$ and a low serum LINC00460 group $(n=44)$ according to the median serum LINC00460 expression. As presented in Tables I and II, serum LINC00460 levels were significantly associated with clinicopathological features, such as FAB 
Table I. Relationship between serum LINC00460 expression and clinicopathologic features in acute myeloid leukemia.

\begin{tabular}{|c|c|c|c|c|}
\hline \multirow[b]{2}{*}{ Clinicopathological features } & \multirow[b]{2}{*}{ No. } & \multicolumn{2}{|c|}{ Serum Linc0062 expression } & \multirow[b]{2}{*}{ P-value } \\
\hline & & High & Low & \\
\hline \multicolumn{5}{|l|}{ Sex } \\
\hline Male & 42 & 18 & 24 & \multirow[t]{2}{*}{0.685} \\
\hline Female & 38 & 18 & 20 & \\
\hline \multicolumn{5}{|l|}{ Age, years } \\
\hline$<60$ & 47 & 21 & 26 & \multirow[t]{2}{*}{0.945} \\
\hline$\geq 60$ & 33 & 15 & 18 & \\
\hline \multicolumn{5}{|l|}{ BM blasts, \% } \\
\hline$<50$ & 41 & 15 & 26 & \multirow[t]{2}{*}{0.079} \\
\hline$\geq 50$ & 39 & 21 & 18 & \\
\hline \multicolumn{5}{|l|}{ PLT counts, $x 10^{9} / 1$} \\
\hline$<50$ & 34 & 18 & 16 & \multirow[t]{2}{*}{0.220} \\
\hline$\geq 50$ & 46 & 18 & 28 & \\
\hline \multicolumn{5}{|l|}{ WBC counts, $x 10^{9} / 1$} \\
\hline$<10$ & 45 & 16 & 29 & \multirow[t]{2}{*}{0.054} \\
\hline$\geq 10$ & 35 & 20 & 15 & \\
\hline \multicolumn{5}{|l|}{ Extramedullary disease } \\
\hline No & 52 & 22 & 30 & \multirow[t]{2}{*}{0.509} \\
\hline Yes & 28 & 14 & 14 & \\
\hline \multicolumn{5}{|l|}{ Complete remission } \\
\hline Yes & 51 & 24 & 27 & \multirow[t]{2}{*}{0.624} \\
\hline No & 29 & 12 & 17 & \\
\hline \multicolumn{5}{|l|}{ Cytogenetics } \\
\hline Favorable & 20 & 5 & 15 & \multirow[t]{3}{*}{0.018} \\
\hline Intermediate & 42 & 20 & 22 & \\
\hline Unfavorable & 18 & 11 & 7 & \\
\hline
\end{tabular}

BM, bone marrow; PLT, platelet; WBC, white blood cells.

classification and cytogenetics. However, there was no significant correlation of LINC00460 expression with other clinical features, including sex, age, white blood cell count, BM blasts, extramedullary disease and CR (Table I).

Association between serum LINC00460 expression and treatment response. After receiving different treatments (chemotherapy and/or targeted therapy), 42 patients achieved CR. To further investigate the effect of serum LINC00460 on the progression of AML, the expression of serum LINC00460 in patients with AML was compared before and after achieving CR. It was demonstrated that serum LINC00460 expression was markedly decreased in patients with AML after treatment, suggesting that serum LINC00460 expression was closely associated with treatment response (Fig. 2).

Prognostic evaluation of LINC00460 expression in patients with $A M L$. Clinical follow-up was conduct to determine the prognostic value of serum LINC00460 expression in patients with AML. The log-rank test and Kaplan-Meier analysis were performed. The results demonstrated that the patients with AML in the low LINC00460 expression group had a significantly longer 5-year overall survival time (Fig. 3A) and recurrence-free survival (Fig. 3B) compared with those in the high expression group. Similar results were obtained in non-M3 subtype cases (non-acute promyelocytic leukemia; Fig. 3C and D). In addition, among the 45 patients with CN-AML, higher expression of LINC00460 was associated with shorter 5-year overall survival (Fig. 3E) and recurrence-free survival (Fig. 3F) compared with the lower expression group.

Univariate analysis identified that FAB classification, cytogenetics and serum LINC00460 expression were significantly correlated with poor overall survival of patients with AML $(\mathrm{P}<0.05$; Table II). Further multivariate analysis demonstrated that serum LINC00460 expression, FAB classification and cytogenetics were independent prognostic indicators of the overall survival of patients with AML (Table II). These data suggested that LINC00460 was a potential prognostic biomarker for patients with AML.

Knockdown of LINC00460 inhibits viability, as well as induces cell cycle arrest and apoptosis in AML cells. Next, 
Table II. Univariate and multivariate analyses of prognostic factors in acute myeloid leukemia.

\begin{tabular}{|c|c|c|c|c|c|c|}
\hline \multirow[b]{2}{*}{ Variables } & \multicolumn{3}{|c|}{ Univariate analysis } & \multicolumn{3}{|c|}{ Multivariate analysis } \\
\hline & Hazard ratio & $95 \% \mathrm{CI}$ & P-value & Hazard ratio & $95 \% \mathrm{CI}$ & P-value \\
\hline $\begin{array}{l}\text { Sex } \\
\text { Male vs. female }\end{array}$ & 1.332 & $0.691-2.412$ & 0.372 & - & - & - \\
\hline $\begin{array}{l}\text { Age, years } \\
<60 \text { vs. } \geq 60\end{array}$ & 1.448 & $0.732-2.578$ & 0.228 & - & - & - \\
\hline $\begin{array}{l}\text { WBC counts } \times 10^{9} / 1 \\
<10 \text { vs. } \geq 10\end{array}$ & 1.541 & $0.811-2.635$ & 0.175 & - & - & - \\
\hline $\begin{array}{l}\text { Blast in BM, } \% \\
<50 \text { vs. } \geq 50\end{array}$ & 1.493 & $0.824-2.674$ & 0.213 & - & - & - \\
\hline $\begin{array}{l}\text { Extramedullary disease } \\
\text { No vs. Yes }\end{array}$ & 1.712 & $0.631-2.215$ & 0.302 & - & - & - \\
\hline $\begin{array}{l}\text { Complete remission } \\
\text { Yes vs. No }\end{array}$ & 1.515 & $0.703-2.113$ & 0.117 & - & - & - \\
\hline $\begin{array}{l}\text { FAB classification } \\
\text { M1-M5 vs. M6-M7 }\end{array}$ & 3.126 & $1.643-5.189$ & 0.004 & 2.916 & $1.352-4.715$ & 0.009 \\
\hline $\begin{array}{l}\text { Cytogenetics } \\
\text { Unfavorable vs. } \\
\text { favorable/intermediate }\end{array}$ & 3.372 & $1.769-5.376$ & 0.003 & 2.747 & $1.116-4.032$ & 0.017 \\
\hline $\begin{array}{l}\text { Serum LINC00899 expression } \\
\text { High vs. low }\end{array}$ & 3.762 & $1.818-6.177$ & 0.001 & 3.015 & $1.462-5.018$ & 0.004 \\
\hline
\end{tabular}

LINC00460, long non-coding RNA 00460; FAB, French-American-British; BM, bone marrow; WBC, white blood cells.

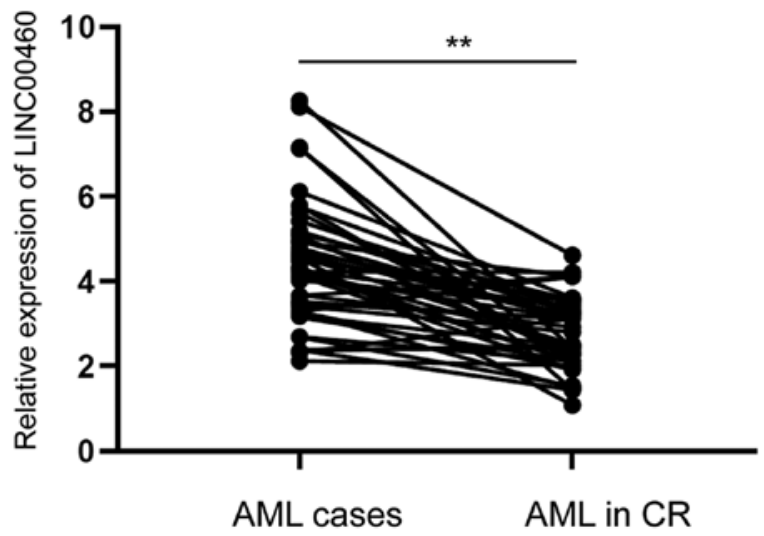

Figure 2. Serum LINC00460 expression levels in patients with AML before and after CR. Serum LINCO00460 expression was measured by reverse transcription-quantitative PCR. ${ }^{* *} \mathrm{P}<0.01$, AML vs AML following complete remission. $\mathrm{CR}$, complete remission; $\mathrm{AML}$, cytogenetically normal-AML; LINC00460, long non-coding RNA 00460.

the function of LINC00460 were investigated in vitro. The expression of LINC00460 was measured in a normal human bone marrow stromal cell line (HS-5) and AML cells (THP-1, KG-1, ME-1 and HL-60) via RT-qPCR. It was found that the expression of LINC00460 was significantly upregulated in AML cells (Fig. 4A).

To further address the biological functions of LINC00460 in AML cells, siRNA-mediated knockdown of LINC00460 was performed in AML cells. The si-LINC00460-transfected cells demonstrated a significant decrease in LINC00460 expression compared with cells transfected with si-NC (Fig. 4B). The MTT assay indicated that the viability of AML cells was significantly inhibited after silencing LINC00460 compared with the control group (Fig. 4C). Cell cycle distribution analysis identified that knockdown of LINC00460 caused cell cycle arrest at the $\mathrm{G}_{2}$ phase in AML cells (Fig. 4D). Moreover, a significant increase in apoptotic AML cells was observed after silencing LINC00460 (Fig. 4E). Western blotting and caspase- 3 activity results also suggested that knockdown LINC00460 induced apoptosis in AML cells (Fig. 4F and G). Taken together, these data indicated that knockdown LINC00460 inhibited viability, as well as induced cell cycle arrest and apoptosis in AML cells.

LINC00460 acts as a sponge of miR-320b. Considering that lncRNAs can act as sponges to bind miRNAs, two bioinformatic tools (TargetScan and StarBase 2.0) were applied for predicting putative miRNAs. The putative binding sites between LINC00460 and miR-320b are presented in Fig. 5A. It was found that the expression of miR-320b was significantly lower in AML cells compared with in HS-5 cells (Fig. 5B). The transfection efficiency of the miR-320b mimic is presented in Fig. 5C. The interaction between miR-320b and LINC00460 was then examined via measuring luciferase activity. The results demonstrated that overexpression of miR-320b 


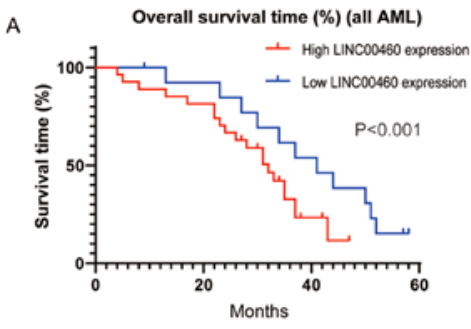

C
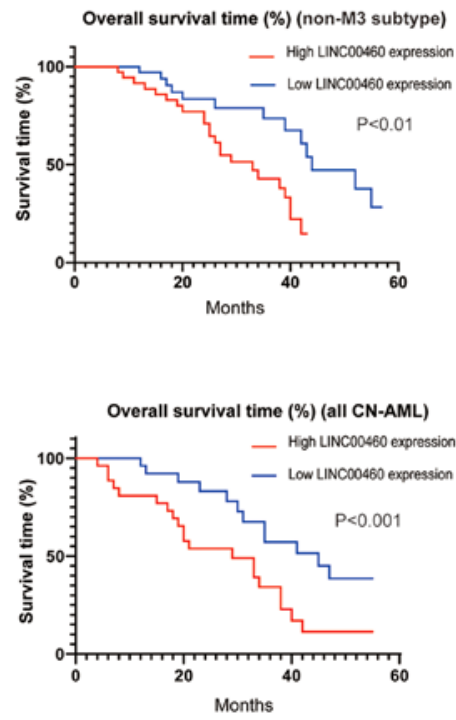

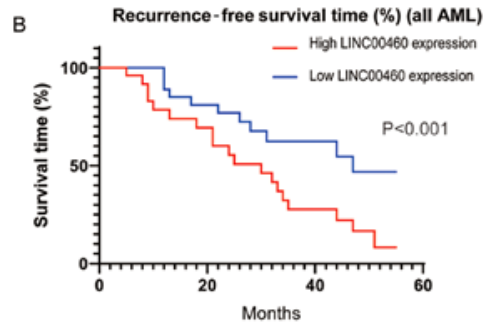

D
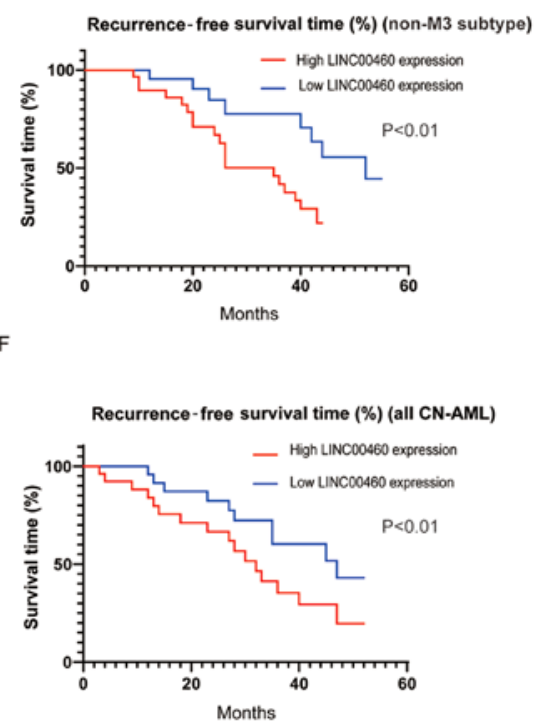

Figure 3. Kaplan-Meier analysis of the overall survival time and recurrence-free survival time of patients with AML with different expression levels of serum LINC00460. All patients with AML with higher serum LINC00460 expression had a (A) poorer overall survival and (B) poorer recurrence-free survival. Patients with non-M3 subtype AML with higher serum LINC00460 expression had a (C) poorer overall survival and (D) poorer recurrence-free survival. All patients with CN-AML with higher serum LINC00460 expression had a (E) poorer overall survival and (F) poorer recurrence-free survival. CN-AML, cytogenetically normal-AML; AML, acute myeloid leukemia; LINC00460, long non-coding RNA 00460.
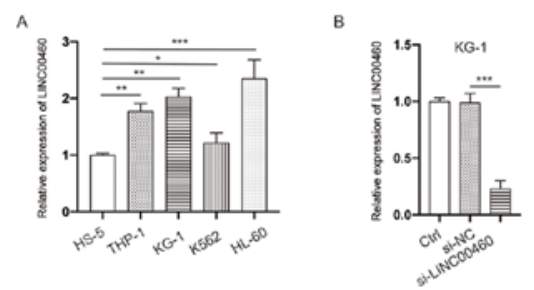

$\mathrm{D}$

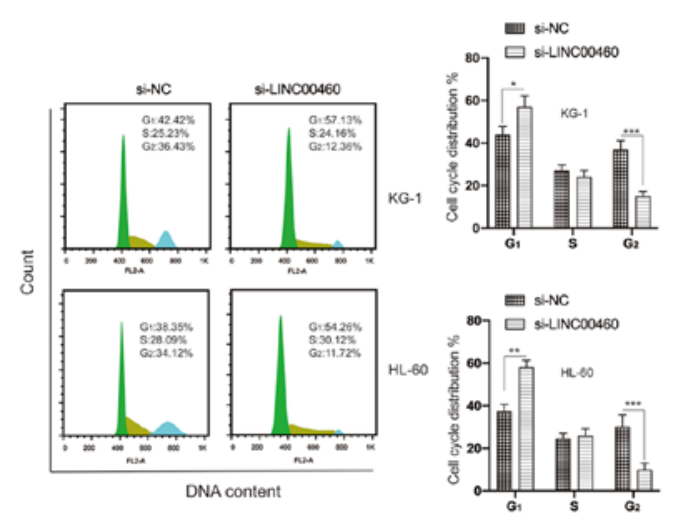

C
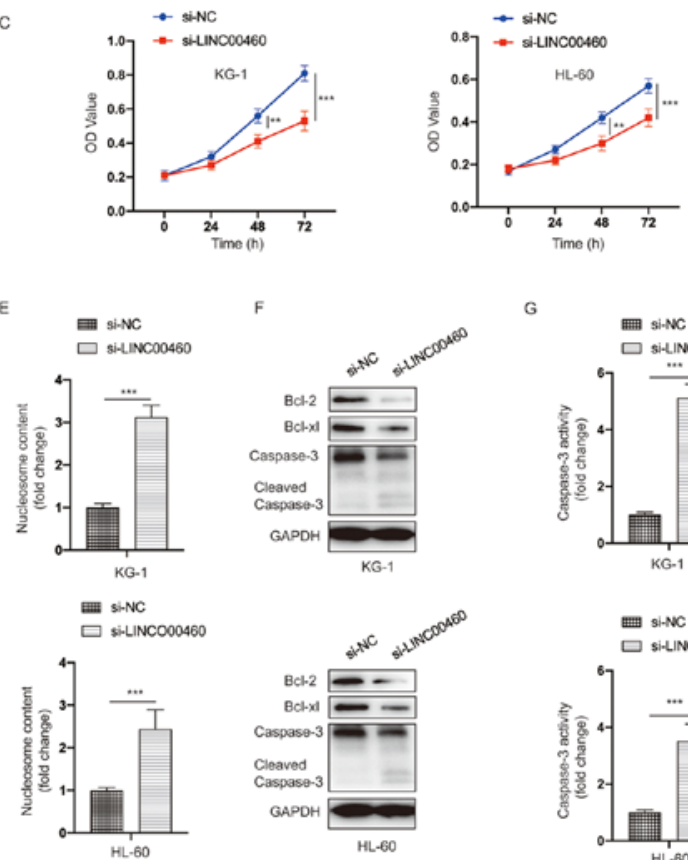

F
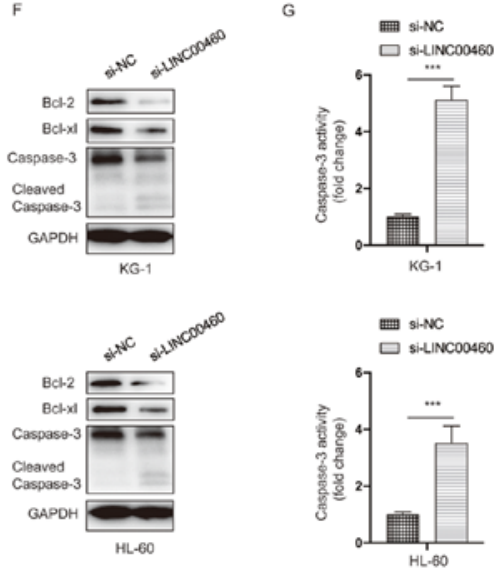

Figure 4. LINC00460 functions as an oncogene in AML cells. (A) Expression of LINC00460 was measured in bone marrow stromal cells (HS-5) and AML cells (THP-1, KG-1, K562 and HL-60). (B) AML cells were transfected as indicated, and the expression of LINC00460 was measured. (C) AML cells were treated as indicated, and cell viability was measured at different time points. (D) AML cells were treated as indicated, and cell cycle distribution was assayed. (E) AML cells were treated as indicated, and cell apoptosis was assayed. (F) AML cells were treated as indicated, and total cell lysates were subjected to western blotting with the specified antibodies. (G) AML cells were treated as indicated, and Caspase-3 activity was assayed. All experiments were conducted $\geq 3$ times. Data are presented as the mean $\pm \mathrm{SD}$. ${ }^{*} \mathrm{P}<0.05 ;{ }^{* *} \mathrm{P}<0.01 ;{ }^{* * *} \mathrm{P}<0.001$. NC, negative control; siRNA, small interfering RNA; AML, acute myeloid leukemia; LINC00460, long non-coding RNA 00460; OD, optical density. 


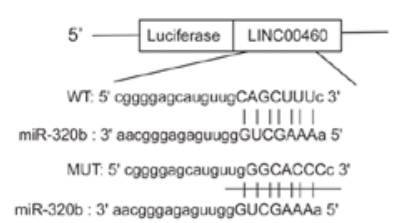

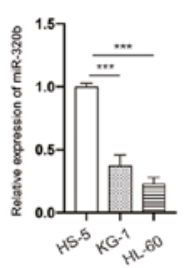

C mR-NC mimc

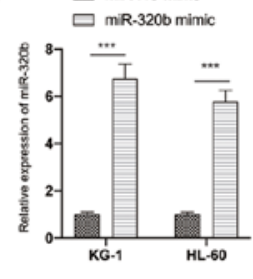

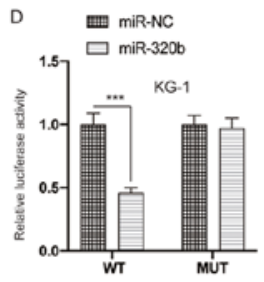

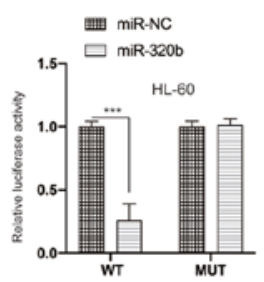

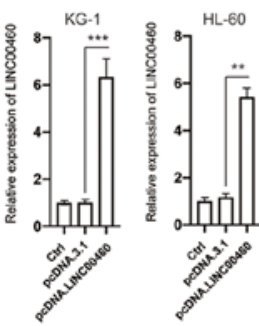
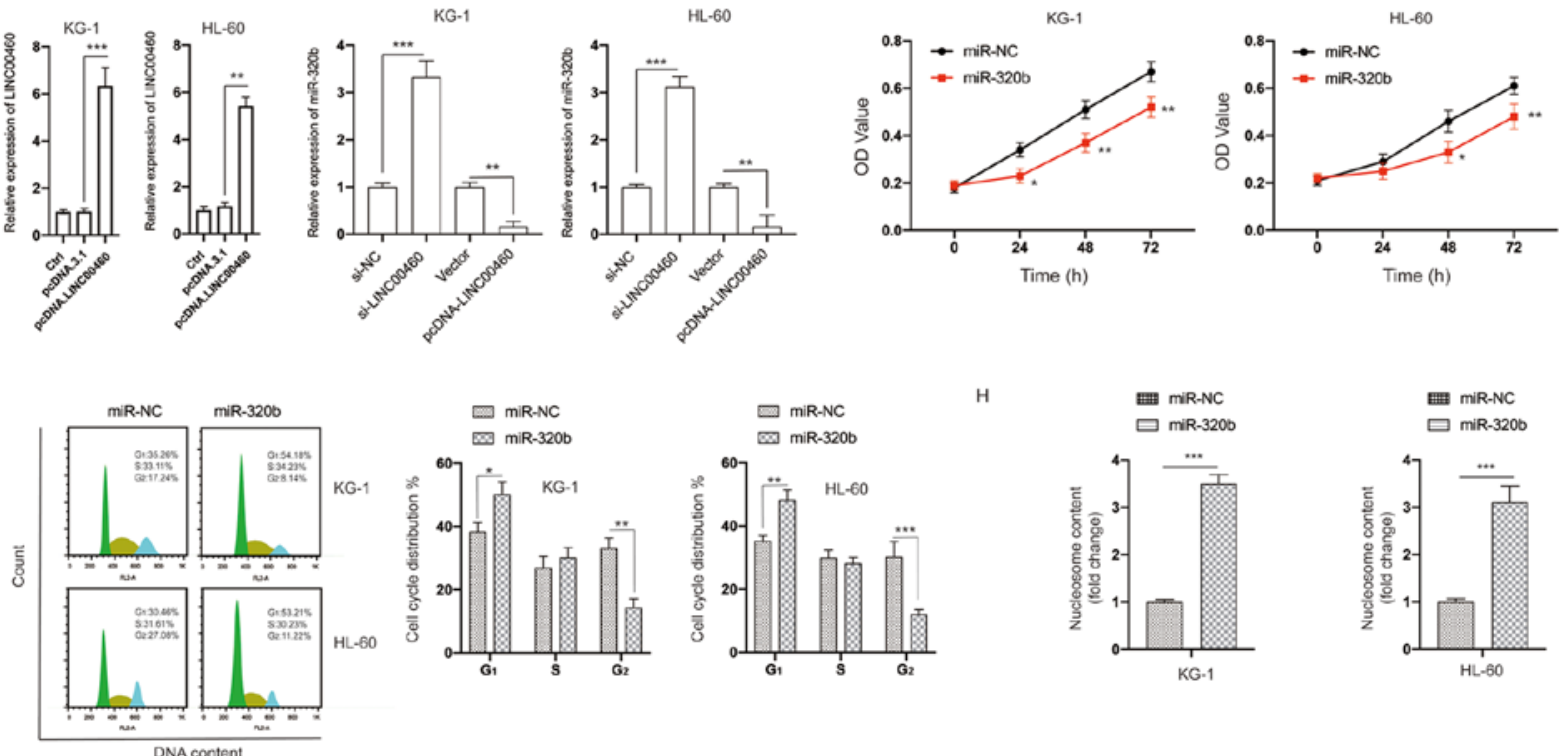

Figure 5. LINC00460 acts as a sponge of miR-320b. (A) Constructed luciferase reporter plasmids containing the predicted WT or MUT miR-320b binding sites on LINC00460. (B) Expression of miR-320b in HS-5, KG-1 and HL-60 cells was measured. (C) KG-1 and HL-60 cells were transfected with miR-NC mimic or miR-320b mimic, the expression of miR-320b was measured via reverse transcription-quantitative PCR. (D) A luciferase reporter assay was performed to measure the luciferase activity in AML cells after co-transfection of miRNA mimics and LINC00460 WT or MUT. (E) AML cells were transfected as indicated, and the expression of miR-320b was measured. (F) AML cells were transfected with miR-320b mimics or miR-NC mimics for the indicated times, and cell viability was measured. (G) AML cells were transfected as indicated, and the cell cycle distribution was assayed. (H) AML cells were transfected as indicated, and cell apoptosis was measured. All experiments were conducted $\geq 3$ times. Data are presented as the mean $\pm \mathrm{SD}$. ${ }^{*} \mathrm{P}<0.05 ;{ }^{* * *} \mathrm{P}<0.01 ;{ }^{* * * *} \mathrm{P}<0.001$. NC, negative control; miR, microRNA; AML, acute myeloid leukemia; LINC00460, long non-coding RNA 00460; OD, optical density; Ctrl, control; WT, wild-type; MUT, mutant.

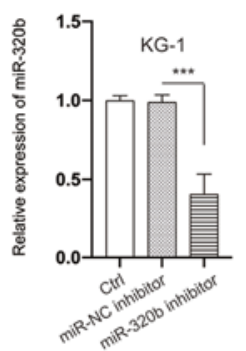

c

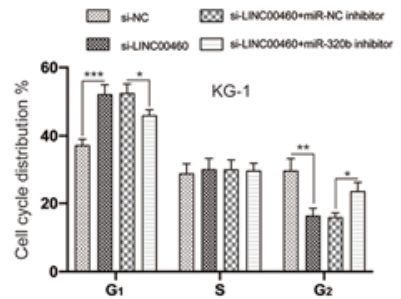

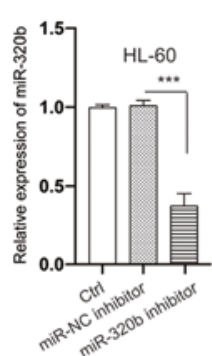

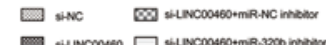

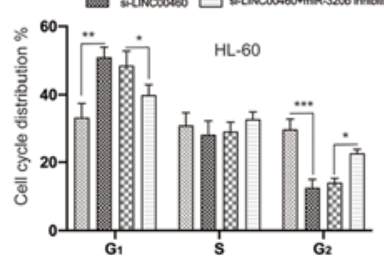

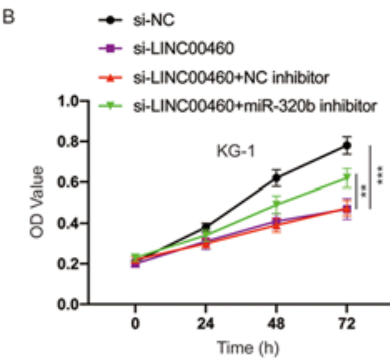

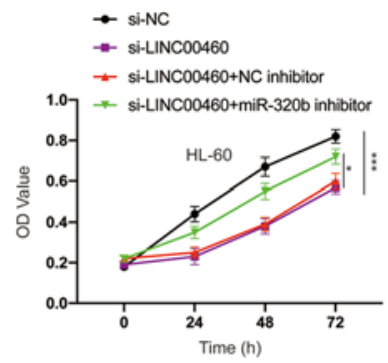

$\mathrm{D}$

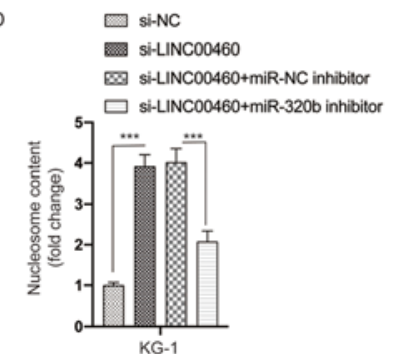

Figure 6. Knockdown of miR-320b suppresses the effects of silencing LINC00460 on AML cells. (A) AML cells were transfected as indicated, and the expression of miR-320b was measured. (B) AML cells were transfected as indicated, and the viability of cells was measured using the MTT assay. (C) AML cells were transfected as indicated, and the cell cycle distribution was detected. (D) AML cells were transfected as indicated, and cell apoptosis was evaluated. All experiments were conducted $\geq 3$ times. Data are presented as the mean $\pm \mathrm{SD}$. ${ }^{*} \mathrm{P}<0.05 ;{ }^{* * *} \mathrm{P}<0.01 ;{ }^{* * * *} \mathrm{P}<0.001$. NC, negative control; miR, microRNA; AML, acute myeloid leukemia; LINC00460, long non-coding RNA 00460; OD, optical density; Ctrl, control; siRNA, small interfering RNA. 
A

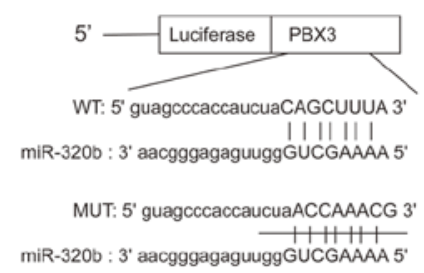

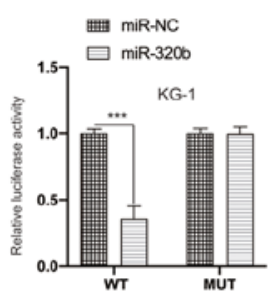

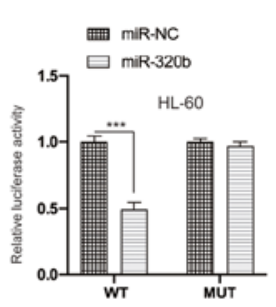

F

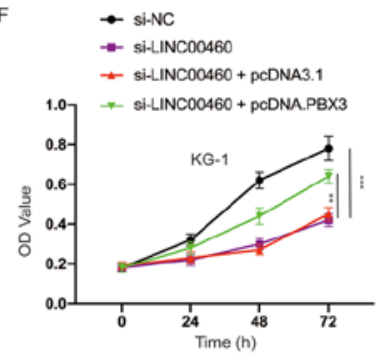

H

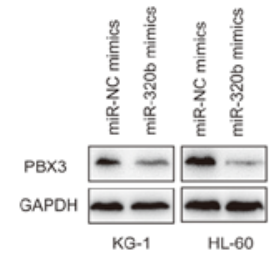

D
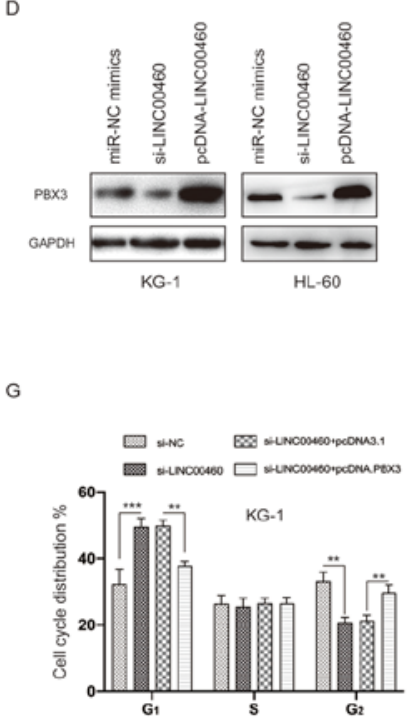

$E$

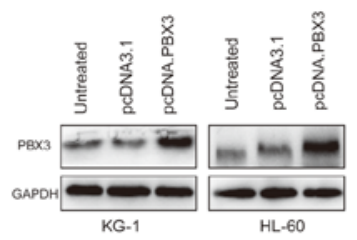

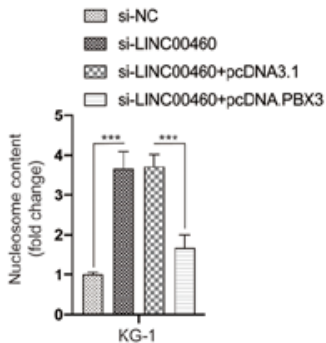
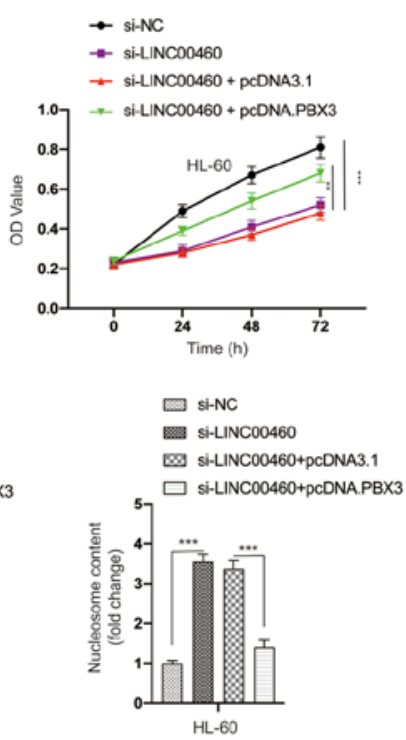

Figure 7. PBX3 is a direct target of miR-320b. (A) Constructed luciferase reporter plasmids containing the predicted WT or MUT miR-320b binding sites on PBX3. (B) A luciferase reporter assay was performed to measure the luciferase activity in AML cells after co-transfection of miRNA mimics and PBX3 WT or MUT. (C) AML cells were transfected with miR-NC mimics or miR-320b mimics and the protein levels of PBX3 measured by western blotting. (D) AML cells were transfected with miR-NC mimics, si-LINC00460 or pcDNA-LINC00460 and the protein levels of PBX3 measured by western blotting. (E) AML cells were transfected with pcDNA3.1 or pcDNA.PBX3 and the protein expression levels of PBX3 measured via western blotting. (F) AML cells were transfected as indicated, and cell viability was measured using the MTT assay. (G) AML cells were transfected as indicated, and the cell cycle distribution was detected. (H) AML cells were transfected as indicated, and cell apoptosis was examined. All experiments were conducted $\geq 3$ times. Data are presented as the mean \pm SD. ${ }^{* *} \mathrm{P}<0.01$; ${ }^{* * *} \mathrm{P}<0.001$. NC, negative control; miR, microRNA; AML, acute myeloid leukemia; LINC00460, long non-coding RNA 00460; OD, optical density; siRNA, small interfering RNA; PBX3, PBX homeobox 3; WT, wild-type; MUT, mutant.

significantly inhibited the luciferase activity of AML cells transfected with LINC00460-WT, while its efficacy was absent with respect to the LINC00460-MUT group (Fig. 5D). The expression of LINC00460 was significantly upregulated following transfection with pcDNA.LINC00460 (Fig. 5E). The expression of miR-320b was significantly decreased by LINC00460 overexpression, but was increased by LINC00460 knockdown in AML cells (Fig. 5E). Further analysis identified that the viability of AML cells was inhibited by transfection with the miR-320b mimic (Fig. 5F). Similar to the knockdown of LINC00460, overexpression of miR-320b caused cell cycle arrest at the $\mathrm{G}_{2}$ phase and increased apoptosis of AML cells (Fig. 5G and H). Thus, these data indicated that LINC00460 acted as a sponge of miR-320b.

Inhibition of miR-320b partially blocks the effects of LINC00460 knockdown on AML cells. To further analyze the correlation between miR-320b and LINC00460, transfection of the miR-320b inhibitor was conducted, which successfully decreased the expression of miR-320b (Fig. 6A). It was found that knockdown of miR-320b partially reversed the effects of silencing LINC00460 on the viability of AML cells (Fig. 6B). Moreover, the cell cycle arrest at the $G_{2}$ phase
(Figs. S1 and 6C) and apoptosis (Fig. 6D) induced by silencing LINC00460 could be partially rescued by knockdown of miR-320b. Therefore, these data further demonstrated the relationship between LINC00460 and miR-320b.

$P B X 3$ is a direct target of $m i R-320 b$. Next, the possible direct targets of miR-320b were investigated. Using bioinformatics analysis, the 3'-UTR of the PBX3 gene was predicted to bind with miR-320b (Fig. 7A). The interaction between miR-320b and PBX3 was further validated via the dual-luciferase reporter assay, which indicated significantly decreased luciferase activity caused by miR-320b mimics in AML cells expressing the WT PBX3 3'-UTR sequence, while there was little change in luciferase activity in cells expressing the MUT PBX3 3'-UTR sequence (Fig. 7B). The transfection of miR-320b mimics decreased the protein expression level of PBX3 in AML cells (Fig. 7C). Moreover, knockdown and overexpression of LINC00460 led to decreased and increase of PBX3 expression in AML cells, respectively (Fig. 7D). This finding suggested that LINC00460 may exert its function via regulation of the miR-320b/PBX3 axis.

To further verify the role of PBX3 in the function of LINC00460, the expression of PBX3 was successfully 
overexpressed in AML cells via transfection of an expression vector (Fig. 7E). The MTT assays results demonstrated that overexpression of $\mathrm{PBX} 3$ partially blocked the inhibitory effects of LINC00460 knockdown on the viability of AML cells (Fig. 7F). Furthermore, overexpression of PBX3 reversed the effects of silencing LINC00460 on the cell cycle distribution (Figs. S2 and 7G) and apoptosis (Fig. 7H) of AML cells. Collectively, these data suggested that PBX3 was a direct target of miR-320b and that LINC00460 exerts its effects, at least, partially via regulation of the miR-320b/PBX3 axis.

\section{Discussion}

AML, characterized by a subpopulation of long-term proliferative progenitor cells, is a common type of hematological malignant tumor that threatens human life (32). Its poor prognosis means it is necessary to identify novel therapeutic agents and sensitive biomarkers of AML (33). In recent years, accumulating evidence has revealed that serum lncRNAs could be applied as potential biomarkers for the diagnosis and prognosis of different malignancies, including AML. For instance, both LINC00265 and LINC00899 are found to be upregulated in the serum of patients with AML and could be used as a potential biomarker for AML $(34,35)$. In the current study, it was identified that serum LINC00460 expression in patients with AML was significantly upregulated compared with that in healthy controls. Moreover, serum LINC00460 expression was significantly increased in AML subjects with poor-risk cytogenetics. ROC analysis demonstrated that serum LINC00460 expression could effectively differentiate patients with AML from healthy controls. Moreover, downregulation of serum LINC00460 was detected in patients with AML with a CR. The present data also indicated that patients with high serum LINC00460 expression had a significantly poorer overall survival time and recurrence-free survival time compared with those with low serum LINC00460 expression. Additionally, serum LINC00460 could serve as an independent prognostic indicator for patients with AML. To the best of our knowledge, the present study was the first report on the clinical significance of serum LINC00460 in patients with AML.

The current findings are consistent with other studies showing that LINC00460 functioned as an oncogene in various types of cancer. For example, Feng et al (36) reported that LINC00460 was significantly upregulated in glioma tissues and cell lines compared with non-tumor healthy tissues. In epithelial ovarian cancer, LINC00460 expression is markedly increased in both cancer tissues and cell lines (17). Moreover, upregulated LINC00460 expression promotes tumorigenicity by binding miR-338-3p in vitro (17). LINC00460 was also observed to be upregulated in both head and neck squamous cell carcinoma (HNSCC) tissues and cell lines, as well as predicted a poor prognosis in patients with HNSCC (37). In breast cancer, upregulation of LINC00460 expression was observed in breast cancer tissues and was found to be associated with aggressive clinical characteristics (38). Furthermore, knockdown of LINC00460 results in the inhibition of viability, migration and invasion of breast cancer cells (38). In a recent study, LINC00460 was found to be notably upregulated in gastric cancer tissues compared with non-tumor tissues, and LINC00460 could be used as an independent prognostic marker in gastric cancer (39).

To date, accumulating evidence suggests that lncRNAs can be released into various body fluids, such as urine, saliva and serum, as a result of cancer cell excretion (40). The easy accessibility of serum and the stability of lncRNA in serum makes IncRNAs ideal biomarkers for the diagnosis and prognosis of cancer. There are several explanations regarding the stability of lncRNAs in serum: i) lncRNAs may be selectively enclosed into membrane-covered vesicles, which can provide protection against degradation; ii) lncRNAs may bind with proteins to avoid degradation; and iii) lncRNAs may fold into stable complex secondary and tertiary structures (41). Although the present study identified the oncogenic role of LINC00460 and its underlying mechanisms in AML, there remain some limitations. First, the clinical sample size was relatively small. Second, most participants were recruited from the same hospital. Therefore, further multicenter cohort studies should be performed in the future to further confirm the current findings. Moreover, it would be interesting to investigate LINC00460 in serum samples of patients with other malignant diseases.

The present study investigated the biological functions of LINC00460 in vitro. It was identified that knockdown of LINC00460 inhibited the viability, as well as induced cell cycle arrest and apoptosis of AML cells. These findings are in line with previous studies, which also reported that LINC00460 acted as an oncogene in lung, colorectal and ovarian cancer cells $(22,42,43)$. Furthermore, Lian et al (15) revealed that inhibition of LINC00460 induced cell cycle arrest at the $\mathrm{G}^{1}$ phase in colorectal cells, while the present study identified that silencing LINC00460 caused cell cycle arrest at the $\mathrm{G}^{2}$ phase. This discrepancy may be caused by the use of different cell lines, and additional investigations are required to further elucidate the role of LINC00460 in the control of cell cycle progression.

It is well known that miRNAs participate widely in the progression of various human cancer types (44). In addition, lncRNAs can act as competing endogenous RNAs to bind and inhibit the functions of miRNAs (45). The present study demonstrated that LINC00460 acted as a sponge of miR-320b, which has been identified as a tumor suppressor in different human cancer types, such as colorectal cancer, glioma, lung cancer and prostate cancer (21-23). Previous studies have reported that the expression and functions of miR-320b in tumorigenesis could be regulated by lncRNAs. For instance, lncRNA $X$ inactive specific transcript can regulate the progression of osteosarcoma by targeting and suppressing miR-320b expression (46). In addition, miR-320b is targeted and repressed by the lncRNA NR2F2-antisense 1 in modulating the tumorigenesis of lung cancer (23). Consistent with previous studies, the present results suggested that miR-320b could be a downstream target of LINC00460, which exerts its function at least partly via regulation of miR-320b.

PBX3 acts as a transcription factor and has been intensively studied in the pathogenesis of AML $(26,27)$. More importantly, inactivation of PBX3 could suppress the stemness and survival of leukemia cells (47). PBX3 was also found to serve essential roles in the tumorigenesis of various solid cancer types, such as colorectal cancer, prostate cancer, gastric 
cancer, cervical cancer and pancreatic cancer (48). Therefore, targeting PBX3 may be a potential strategy for the treatment of cancer, including AML. The present study identified novel mechanistic events involved in the regulation of PBX3, which may be applied in the field of treatment of various cancer types.

In conclusion, the present study provided evidence that serum LINC00460 expression was significantly upregulated in patients with AML, and was closely associated with poor clinical outcome and unfavorable clinical variables. To the best of our knowledge, the present study identified the role of LINC00460 in AML for the first time. Furthermore, it was suggested that PBX3, which may also be a potential target for AML, could be negatively regulated by miR-320b. The in vitro studies demonstrated that LINC00460 exerted its functions via the miR-320b/PBX3 axis in AML cells. Therefore, LINC00460 may be used as a potential indicator and target for the prognosis and treatment of AML.

\section{Acknowledgements}

The authors thank Dr Wenming Wang (Laboratory of Biochemistry, Shanghai University of Science and Technology) for helpful suggestions during the present study.

\section{Funding}

No funding was received.

\section{Availability of data and materials}

The datasets used and/or analyzed during the current study are available from the corresponding author on reasonable request.

\section{Authors' contributions}

QZ performed the experiments and drafted the manuscript, $\mathrm{ZJ}$ performed the experiments, $\mathrm{XZ}$ conducted the statistical analysis, TJ repeated some of the experiments and LX designed the study and drafted the manuscript. All authors reviewed and approved the final manuscript.

\section{Ethics approval and consent to participate}

This study was approved by the Ethics Committee of Wenzhou Medical University. Written informed consent was obtained from all patients prior to participation in the study.

\section{Patient consent for publication}

Not applicable.

\section{Competing interests}

The authors declare that they have no competing interests.

\section{References}

1. Courville EL, Wu Y, Kourda J, Roth CG, Brockmann J, Muzikansky A, Fathi AT, de Leval L, Orazi A and Hasserjian RP: Clinicopathologic analysis of acute myeloid leukemia arising from chronic myelomonocytic leukemia. Mod Pathol 26: 751-761, 2013.
2. Siegel RL, Miller KD and Jemal A: Cancer statistics, 2020. CA Cancer J Clin 70: 7-30, 2020.

3. Appelbaum FR, Gundacker H, Head DR, Slovak ML, Willman CL, Godwin JE, Anderson JE and Petersdorf SH: Age and acute myeloid leukemia. Blood 107: 3481-3485, 2006.

4. Döhner H, Weisdorf DJ and Bloomfield CD: Acute myeloid leukemia. N Engl J Med 373: 1136-1152, 2015.

5. Christen F, Hoyer K, Yoshida K, Hou HA, Waldhueter N, Heuser M, Hills RK, Chan W, Hablesreiter R, Blau O, et al: Genomic landscape and clonal evolution of acute myeloid leukemia with $\mathrm{t}(8 ; 21)$ : An international study on 331 patients. Blood 133: 1140-1151, 2019.

6. Gregory TK, Wald D, Chen Y, Vermaat JM, Xiong Y and Tse W: Molecular prognostic markers for adult acute myeloid leukemia with normal cytogenetics. J Hematol Oncol 2: 23, 2009.

7. Kurosawa S, Miyawaki S, Yamaguchi T, Kanamori H, Sakura T, Moriuchi Y, Sano F, Kobayashi T, Yasumoto A, Hatanaka K, et al: Prognosis of patients with core binding factor acute myeloid leukemia after first relapse. Haematologica 98: 1525-1531, 2013.

8. Yang L, Froberg JE and Lee JT: Long noncoding RNAs: Fresh perspectives into the RNA world. Trends Biochem Sci 39: 35-43, 2014.

9. Böhmdorfer G and Wierzbicki AT: Control of chromatin structure by long noncoding RNA. Trends Cell Biol 25: 623-632, 2015.

10. Kung JT, Colognori D and Lee JT: Long noncoding RNAs: Past, present, and future. Genetics 193: 651-669, 2013.

11. Yu R, Yao J and Ren Y: A novel circRNA, circNUP98, a potential biomarker, acted as an oncogene via the miR-567/PRDX3 axis in renal cell carcinoma. J Cell Mol Med 24: 10177-10188, 2020.

12. Xing CY, Hu XQ, Xie FY, Yu ZJ, Li HY, Bin-Zhou, Wu JB, Tang LY and Gao SM: Long non-coding RNA HOTAIR modulates c-KIT expression through sponging miR-193a in acute myeloid leukemia. FEBS Lett 589: 1981-1987, 2015.

13. Liang Y, Wu Y, Chen X, Zhang S, Wang K, Guan X, Yang K, Li J, Bai Y: A novel long noncoding RNA linc00460 up-regulated by $\mathrm{CBP} / \mathrm{P} 300$ promotes carcinogenesis in esophageal squamous cell carcinoma. Biosci Rep 37: BSR20171019, 2017.

14. Yue QY and Zhang Y: Effects of Linc00460 on cell migration and invasion through regulating epithelial-mesenchymal transition (EMT) in non-small cell lung cancer. Eur Rev Med Pharmacol Sci 22: 1003-1010, 2018.

15. Lian Y, Yan C, Xu H, Yang J, Yu Y, Zhou J, Shi Y, Ren J, Ji G and Wang K: A novel lncRNA, LINC00460, affects cell proliferation and apoptosis by regulating KLF2 and CUL4A expression in colorectal cancer. Mol Ther Nucleic Acids 12: 684-697, 2018.

16. Wang F, Liang S, Liu X, Han L, Wang J and Du Q: LINC00460 modulates KDM2A to promote cell proliferation and migration by targeting miR-342-3p in gastric cancer. Onco Targets Ther 11: 6383-6394, 2018

17. Liu X, Wen J, Wang $\mathrm{H}$ and Wang Y: Long non-coding RNA LINC00460 promotes epithelial ovarian cancer progression by regulating microRNA-338-3p. Biomed Pharmacother 108: 1022-1028, 2018

18. Lian H, Xie P, Yin N, Zhang J, Zhang X, Li J and Zhang C: Linc00460 promotes osteosarcoma progression via miR-1224-5p/FADS1 axis. Life Sci 233: 116757, 2019.

19. Sayed D and Abdellatif M: MicroRNAs in development and disease. Physiol Rev 91: 827-887, 2011.

20. Liao Q, Wang B, Li X and Jiang G: miRNAs in acute myeloid leukemia. Oncotarget 8: 3666-3682, 2017.

21. Lv QL, Du H, Liu YL, Huang YT, Wang GH, Zhang X, Chen SH and Zhou HH: Low expression of microRNA-320b correlates with tumorigenesis and unfavorable prognosis in glioma. Oncol Rep 38: 959-966, 2017.

22. Wang H, Cao F, Li X, Miao H, e J, Xing J and Fu CG: miR-320b suppresses cell proliferation by targeting c-Myc in human colorectal cancer cells. BMC Cancer 15: 748, 2015.

23. Zhang S, Zhang X, Sun Q, Zhuang C, Li G, Sun L and Wang H: LncRNA NR2F2-AS1 promotes tumourigenesis through modulating BMI1 expression by targeting miR-320b in non-small cell lung cancer. J Cell Mol Med 23: 2001-2011, 2019.

24. Lieb V, Weigelt K, Scheinost L, Fischer K, Greither T, Marcou M, Theil G, Klocker H, Holzhausen HJ, Lai X, et al: Serum levels of miR-320 family members are associated with clinical parameters and diagnosis in prostate cancer patients. Oncotarget 9: 10402-10416, 2017.

25. Li Z, Zhang Z, Li Y, Arnovitz S, Chen P, Huang H, Jiang X, Hong GM, Kunjamma RB, Ren H, et al: PBX3 is an important cofactor of HOXA9 in leukemogenesis. Blood 121: 1422-1431, 2013. 
26. Li Z, Chen P, Su R,Hu C,Li Y,Elkahloun AG,Zuo Z, Gurbuxani S, Arnovitz S, Weng H, et al: PBX3 and MEIS1 cooperate in hematopoietic cells to drive acute myeloid leukemias characterized by a core transcriptome of the MLL-rearranged disease. Cancer Res 76: 619-629, 2016.

27. Dickson GJ, Liberante FG, Kettyle LM, O'Hagan KA, Finnegan DP, Bullinger L, Geerts D, McMullin MF, Lappin TR, Mills KI, et al: HOXA/PBX3 knockdown impairs growth and sensitizes cytogenetically normal acute myeloid leukemia cells to chemotherapy. Haematologica 98: 1216-1225, 2013.

28. Müller-Berndorff H, Haas PS, Kunzmann R, Schulte-Mönting J and Lübbert $\mathrm{M}$ : Comparison of five prognostic scoring systems, the French-American-British (FAB) and World Health Organization (WHO) classifications in patients with myelodysplastic syndromes: Results of a single-center analysis. Ann Hematol 85: 502-513, 2006.

29. Yu R, Yu BX, Chen JF, Lv XY, Yan ZJ, Cheng Y and Ma Q Anti-tumor effects of Atractylenolide I on bladder cancer cells. J Exp Clin Cancer Res 35: 40, 2016.

30. Livak KJ and Schmittgen TD: Analysis of relative gene expression data using real-time quantitative PCR and the 2(-Delta Delta C(T)) Method. Methods 25: 402-408, 2001.

31. Wang ML and Bailey NG: Acute myeloid leukemia genetics: Risk stratification and implications for therapy. Arch Pathol Lab Med 139: 1215-1223, 2015.

32. Carneiro BA, Altman JK, Kaplan JB, Ossenkoppele G, Swords R Platanias LC and Giles FJ: Targeted therapy of acute myeloid leukemia. Expert Rev Anticancer Ther 15: 399-413, 2015.

33. Estey EH: Acute myeloid leukemia: 2013 update on risk-stratification and management. Am J Hematol 88: 318-327, 2013.

34. Wang Y, Li Y, Song HQ and Sun GW: Long non-coding RNA LINC00899 as a novel serum biomarker for diagnosis and prognosis prediction of acute myeloid leukemia. Eur Rev Med Pharmacol Sci 22: 7364-7370, 2018.

35. Ma L, Kuai WX, Sun XZ, Lu XC and Yuan YF: Long noncoding RNA LINC00265 predicts the prognosis of acute myeloid leukemia patients and functions as a promoter by activating PI3K-AKT pathway. Eur Rev Med Pharmacol Sci 22: 7867-7876, 2018.

36. Feng L, Rao M, Zhou Y, Zhang Y and Zhu Y: Long noncoding RNA 00460 (LINC00460) promotes glioma progression by negatively regulating miR-320a. J Cell Biochem 120: 9556-9563, 2019.

37. Xie X, Xiong G, Wang Q, Ge Y and Cui X: Long non-coding RNA LINC00460 promotes head and neck squamous cell carcinoma cell progression by sponging miR-612 to up-regulate AKT2. Am J Transl Res 11: 6326-6340, 2019.
38. Zhu Y, Yang L, Chong QY, Yan H, Zhang W, Qian W, Tan S, Wu Z, Lobie PE and Zhu T: Long noncoding RNA Linc00460 promotes breast cancer progression by regulating the miR-489-5p/FGF7/AKT axis. Cancer Manag Res 11: 5983-6001, 2019.

39. Yang J, Lian Y, Yang R, Lian Y, Wu J, Liu J, Wang K and Xu H: Upregulation of IncRNA LINC00460 facilitates GC progression through epigenetically silencing CCNG2 by EZH2/LSD1 and indicates poor outcomes. Mol Ther Nucleic Acids 19: 1164-1175, 2020.

40. Pardini B, Sabo AA, Birolo G and Calin GA: Noncoding RNAs in extracellular fluids as cancer biomarkers: The new frontier of liquid biopsies. Cancers (Basel) 11: 1170, 2019.

41. Chiabotto G, Gai C, Deregibus MC and Camussi G: Salivary extracellular vesicle-associated exRNA as cancer biomarker. Cancers (Basel) 11: 891, 2019.

42. Li K, Sun D, Gou Q, Ke X, Gong Y, Zuo Y, Zhou JK, Guo C, Xia Z, Liu L, et al: Long non-coding RNA linc00460 promotes epithelial-mesenchymal transition and cell migration in lung cancer cells. Cancer Lett 420: 80-90, 2018.

43. Wang X, Mo FM, Bo H, Xiao L, Chen GY, Zeng PW, Huang YN, Lei Z, Yuan WJ and Chen ZH: Upregulated expression of long non-coding RNA, LINC00460, suppresses proliferation of colorectal cancer. J Cancer 9: 2834-2843, 2018.

44. Croce CM and Calin GA: miRNAs, cancer, and stem cell division. Cell 122: 6-7, 2005.

45. Mercer TR, Dinger ME and Mattick JS: Long non-coding RNAs: Insights into functions. Nat Rev Genet 10: 155-159, 2009.

46. Wu X, Dinglin X, Wang X, Luo W, Shen Q, Li Y, Gu L, Zhou Q, Zhu H, Li Y, et al: Long noncoding RNA XIST promotes malignancies of esophageal squamous cell carcinoma via regulation of miR-101/EZH2. Oncotarget 8: 76015-76028, 2017.

47. Zhang W, Zhao C, Zhao J, Zhu Y, Weng X, Chen Q, Sun H, Mi JQ, Li J, Zhu J, et al: Inactivation of PBX3 and HOXA9 by down-regulating H3K79 methylation represses NPM1-mutated leukemic cell survival. Theranostics 8: 4359-4371, 2018.

48. Morgan R and Pandha HS: PBX3 in cancer. Cancers (Basel) 12: 431,2020

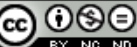

This work is licensed under a Creative Commons Attribution-NonCommercial-NoDerivatives 4.0 International (CC BY-NC-ND 4.0) License. 